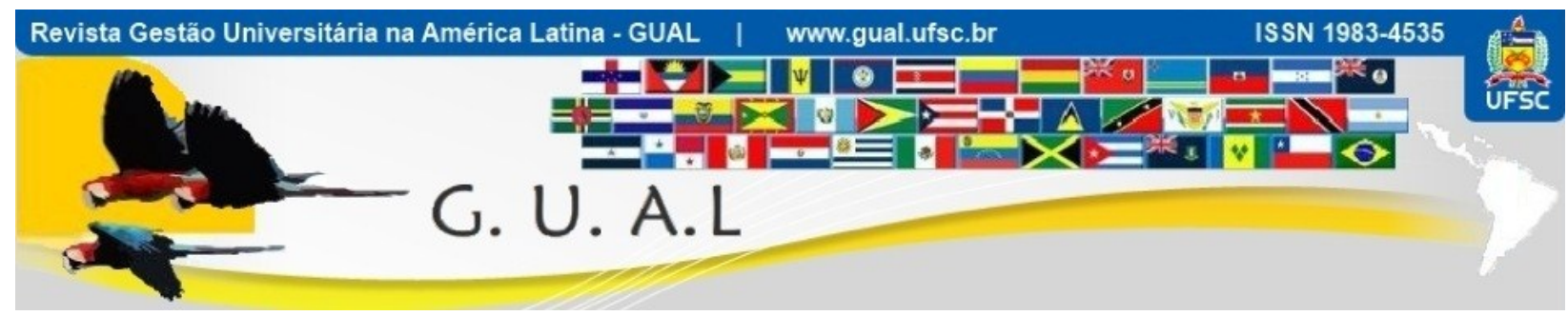

DOI: http://dx.doi.org/10.5007/1983-4535.2012v5n4p43

\title{
A GESTÃO DA PÓS-GRADUAÇÃO NO BRASIL ATRAVÉS DE SEUS PLANOS NACIONAIS: OS DESAFIOS DOS GESTORES DE CURSOS
}

\section{MANAGEMENT OF POST-GRADUATE COUSES IN BRAZIL: THE CHALLENGES OF COURSES MANAGERS}

Recebido em 16/novembro/2012

Aprovado em 07/dezembro/2012

Sistema de Avaliação: Double Blind Review

Esta obra está sob uma Licença Creative Commons Atribuição-Uso. 


\title{
RESUMO
}

O artigo tem por objetivo analisar a gestão da pós-graduação brasileira, no período de 1975 a 2010, através dos cinco primeiros planos nacionais de pós-graduação, destacando os desafios dos gestores de cursos nesse contexto. A metodologia adotada foi a pesquisa bibliográfica e documental, por meio de uma abordagem histórica e qualitativa. Através da análise dos planos nacionais de pós-graduação e do contexto político e econômico em que vigoraram, por meio da leitura de documentos oficiais e de autores que abordam as políticas de pós-graduação, foi possível observar diferentes demandas ao longo do período, como: regulamentação e padronização das atividades de pós-graduação (I PNPG), melhoria da qualidade dos cursos (II PNPG), desenvolvimento da pesquisa na universidade (III PNPG), descentralização da gestão e adequação ao novo modelo de avaliação de cursos (IV PNPG) e diversificação do sistema através da proposição de novos modelos (V PNPG). Concluiu-se que, embora essas demandas tenham tornado a gestão dos programas uma atividade cada vez mais complexa, as políticas e proposições dos PNPG contribuíram para o desenvolvimento da pós-graduação brasileira e para o reconhecimento de sua excelência, em âmbito nacional e internacional.

Palavras-chave: Gestão educacional. Planos Nacionais de Pós-Graduação. Políticas públicas. Pós-graduação. Ensino superior.

\begin{abstract}
The article aims to analyze the management of post-graduate courses in the period from 1975 to 2010, through the first five national post-graduate plans, highlighting the challenges of courses managers in that context. The methodology used was the literature and documental research with a historical and qualitative approach. Through the analysis of national postgraduate plans and the political and economic context in which they operated and through the analysis of official documents as well as authors that study the post-graduate policies, different demands throughout the period were observed such as: the regulation and standardization of the post-graduate activities (I PNPG), the improvement the courses quality (II PNPG), development of university research (III PNPG), decentralization of management and adaptation to the new assessment model courses (IV PNPG ) and system diversification by proposing new models (V PNPG). In conclusion, although these claims have turned program management into an increasingly complex activity, policies and proposals of PNPGs contributed to the development of Brazilian post-graduate courses and also to the recognition of its excellence, both nationally and internationally.
\end{abstract}

Keywords: Education Management. National plans of post-graduate studies. Public policy. Post-graduate courses. Higher education. 


\section{A GESTÃO DA PÓS-GRADUAÇÃO NO BRASIL ATRAVÉS DE SEUS PLANOS NACIONAIS: OS DESAFIOS DOS GESTORES DE CURSOS \\ DOI: http://dx.doi.org/10.5007/1983-4535.2012v5n4p43}

\section{INTRODUÇÃO E CONSIDERAÇÕES METODOLÓGICAS}

A pós-graduação brasileira tem reconhecimento internacional e apresenta números de evolução significativos. Nos anos 70 eram aproximadamente 500 cursos de mestrado e 200 de doutorado. Em 2010, eram 2.700 cursos de mestrado e 1.600 de doutorado e ainda 360 cursos de mestrado profissional, modalidade criada a partir dos anos $2000^{\mathrm{i}}$. Essa evolução se deu mediante esforços políticos e acadêmicos, realizados ao longo das últimas décadas. Buscando compreender a evolução do sistema de pós-graduação pelo prisma da gestão, o presente artigo tem como objetivo analisar as propostas para a gestão de programas de pós-graduação, no período de 1975 a 2010, subjacentes aos cinco primeiros Planos Nacionais de Pós-Graduação no Brasil, período de grande crescimento da pós-graduação brasileira. A pesquisa buscou observar os contextos políticos e econômicos em que os planos foram produzidos, os problemas identificados na pós-graduação, as diretrizes, ações e metas propostas, o foco de cada documento e as observações em relação à avaliação da pós-graduação.

A Coordenação de Aperfeiçoamento de Pessoal de Nível Superior (CAPES) é o órgão responsável pela elaboração dos Planos Nacionais de Educação e desempenha no Brasil um papel estruturante na expansão e consolidação da pós-graduação stricto sensu (mestrado e doutorado), sendo responsável por sua avaliação, pelo acesso e divulgação da produção científica brasileira; pelos investimentos na formação de recursos de alto nível no país e exterior; pela promoção da cooperação científica internacional, entre outros.

A pesquisa realizada para a elaboração do artigo foi bibliográfica e documental, por meio de uma abordagem histórica e qualitativa, e se efetivou através do estudo dos planos nacionais de pós-graduação publicados (I, II, III e V PNPG) e de um não publicado (IV PNPG), assim como do estudo de documentos oficiais relacionados à elaboração e contextualização dos mesmos. Também foi especialmente útil o estudo de autores que abordam as temáticas relativas às experiências e políticas na área de gestão no ensino superior e na pós-graduação no Brasil.O recorte de nossa análise será o período de 1974 a 2010, em que estiveram em vigor os primeiros cinco planos. Embora o quarto plano não tenha sido publicado, as discussões para a sua elaboração subsidiaram as políticas implantadas pela Capes no período. 


\section{A GESTÃO DA PÓS-GRADUAÇÃO NO BRASIL ATRAVÉS DE SEUS PLANOS NACIONAIS: OS DESAFIOS DOS GESTORES DE CURSOS \\ DOI: http://dx.doi.org/10.5007/1983-4535.2012v5n4p43}

\section{A GESTÃo DA PÓS-GRADUAÇÃO BRASILEIRA ATRAVÉS DE SEUS PLANOS NACIONAIS}

A seguir, apresentamos as características do contexto político em que foi formulado cada um dos planos analisados e suas principais determinações.

\section{Plano Nacional de Pós-Graduação (I PNPG - 1975/1979)}

Ainda no período ditatorial, houve a aprovação do I Plano Nacional de Pós-Graduação (PNPG) do país. Ele foi resultado dos trabalhos iniciais do Conselho Nacional de PósGraduação, instituído pelo Ministério da Educação em 1973. O plano foi apresentado num período em que a ditadura militar começava a perder sua legitimidade no Brasil. A insatisfação se dava em virtude tanto do contexto econômico, de recessão e inflação crescentes, como do crescimento dos ideais neoliberais no contexto internacional, que defendiam a mundialização do capital e do regime democrático americano. Uma grande frente popular mobilizou-se em torno do emergente Movimento Democrático Brasileiro (MDB), criando as bases para uma rearticulação da sociedade civil, que passou a reencaminhar, por meio dos vários canais de expressão reconstruídos, projetos de mudança social para o país. Com isso, o governo viu-se obrigado a atenuar a repressão e a buscar o apoio da sociedade civil, adotando em diferentes planos de governo o discurso da necessidade de desenvolvimento econômico aliado à distribuição de renda. E nesse contexto a educação toma lugar de destaque, por ser considerada propulsora do desenvolvimento do país e da ascensão social dos indivíduos (LIRA, 2010; VAROTTO, 2007).

A introdução do I PNPG aponta que as atividades de pós-graduação estavam assumindo uma importância estratégica para o país, na medida em que o ensino superior é um setor de formação de recursos humanos para os demais níveis de ensino e para a sociedade, e que a pós-graduação forma os profissionais para atuar nesse nível de ensino e na pesquisa. $\mathrm{O}$ documento foi constituído de três partes principais: "análise da evolução da pós-graduação no Brasil", "objetivos e diretrizes gerais" e "programas e metas de expansão", que expressavam os principais objetivos em relação às atividades de pós-graduação naquele momento. $\mathrm{O}$ governo entendia como estratégico o ensino de pós-graduação para o país e tinha intenção de orientar o seu crescimento, estabelecendo diretrizes a serem seguidas.

$\mathrm{Na}$ "Análise da evolução da pós-graduação" foi exposta a fragilidade das informações relativas a esse nível de ensino, na época, verificada na ressalva de que os 


\section{A GESTÃO DA PÓS-GRADUAÇÃO NO BRASIL ATRAVÉS DE SEUS PLANOS NACIONAIS: OS DESAFIOS DOS GESTORES DE CURSOS \\ DOI: http://dx.doi.org/10.5007/1983-4535.2012v5n4p43}

números apresentados eram “(...) estimativas iniciais, extraidas a partir de amostras incompletas e com critérios não totalmente definidos de classificação e agregação". A maior parte do tópico foi dedicada à análise do processo de crescimento da pós-graduação e foram apontados, como pontos problemáticos, a instabilidade e a fragilidade institucional das atividades, que cresciam de forma isolada e desarticulada, com insuficiente apoio das instituições de ensino e dos órgãos diretores da política educacional e ainda, com uma heterogeneidade de fontes e formas de financiamento. Em geral, as atividades de pósgraduação vinham sendo realizadas por iniciativa de professores e pesquisadores, que as financiavam com recursos externos ao orçamento das universidades. Estes grupos adotavam procedimentos administrativos próprios, o que gerava conflitos nas universidades e falta de controle no nível federal. Diante desse quadro, o Plano alertava para a necessidade de planejamento e articulação dessas atividades, a fim de se superar os principais problemas diagnosticados, relativos: (a) à instabilidade das atividades de pós-graduação, (b) ao baixo desempenho dos cursos, já que a maior parte dos alunos matriculados não chegava a concluir os estudos; e (c) ao crescimento insuficiente e concentrado nas grandes capitais.

Assim, na seção "Objetivos e diretrizes gerais" determinou-se que caberia à pósgraduação: formar professores para o magistério universitário, formar pesquisadores para o trabalho científico e preparar profissionais de nível elevado para o mercado de trabalho. Para isso, foram eleitas três diretrizes que orientariam as iniciativas: $\left(1^{a}\right)$ institucionalizar $o$ sistema, $\left(2^{\circ}\right)$ elevar os seus atuais padrões de desempenho e racionalizar a utilização dos recursos e $\left(3^{\circ}\right)$ planejar sua expansão. O plano conceitua cada diretriz e as medidas a serem tomadas em cada nível institucional, determinando o prazo de cinco anos para que as mesmas fossem implantadas.

$\mathrm{Na}$ diretriz que trata da institucionalização do sistema de pós-graduação foram observadas as modalidades de ensino que ele abarcava ${ }^{\mathrm{ii}}$ e os vários níveis institucionais de coordenação, planejamento e execução, que envolvia. Em um sistema desarticulado e fragmentado, a determinação dos níveis institucionais e as suas respectivas atribuições cumpriam um papel importante, na medida em que muitos órgãos podiam estar concorrendo entre si. Entretanto, ao determinar as atribuições de cada nível, coube aos elaboradores do plano, representantes do governo, determinar a função de cada ente. Nessa divisão, competiu à base do sistema (universidades e centros de pesquisa) executar o que era determinado pelo topo da pirâmide (órgãos centrais do governo federal). Apontando que a consolidação 


\section{A GESTÃO DA PÓS-GRADUAÇÃO NO BRASIL ATRAVÉS DE SEUS PLANOS NACIONAIS: OS DESAFIOS DOS GESTORES DE CURSOS \\ DOI: http://dx.doi.org/10.5007/1983-4535.2012v5n4p43}

institucional e estabilização financeira levariam a um processo de natureza "políticoadministrativa", o documento falava diretamente aos gestores das universidades e dos cursos, orientando-os para uma "resolução harmônica" de tal processo, através da adequação dos procedimentos existentes a uma "estrutura funcional e hierárquica já conhecida".

Para atender a diretriz referente à elevação dos padrões de desempenho, o plano define a pós-graduação como um sistema de trabalho, de natureza pedagógica e científica, que necessita de recursos humanos e materiais para se concretizar adequadamente. E indica medidas a serem tomadas: (a) pelos cursos, relativas ao processo de seleção dos estudantes, regime de trabalho e concessão de bolsas, processos pedagógicos e produção científica e regime de trabalho dos docentes; (b) pela universidade, relativas a programas institucionais de capacitação docente, intercâmbios e racionalização administrativa e, por fim, (c) a nível nacional, relativas à alocação de recursos, assessoria técnica, e credenciamento dos cursos quando de sua implantação, pois até então esse processo acontecia a posteriori.

E por fim, na diretriz sobre o Planejamento da expansão, além de serem feitas considerações para um planejamento eficaz e sobre a natureza dinâmica do crescimento da pós-graduação, são dadas orientações a serem seguidas em nível nacional e nas universidades. A responsabilidade por minimizar as linhas de pressão sobre a pós-graduação através da integração desta com o sistema universitário e, no nível das universidades, a definição das demandas atuais e futuras de pessoal, recursos necessários e a elaboração de projetos específicos para novos cursos. É importante destacar que as diretrizes "elevação dos padrões de desempenho" e "planejamento da expansão" estimulam mudanças significativas em relação ao papel dos cursos, e não apenas da universidade ou instituição. A partir desse momento, termos como "racionalidade administrativa", "informações estatísticas", "elaboração de projetos", entre outros, estarão diretamente relacionados com a gestão dos cursos e programas.

E finalmente, na terceira parte do plano, dedicada a "Programas e Metas de Expansão", foram definidas as linhas gerais de expansão projetadas para o quinquênio 1975/1979. Depois de discutir a natureza da programação, os principais critérios e limitações, foi determinada, como Meta1, a titulação de 16.800 mestres e 1.400 doutores no período; uma meta ambiciosa, tendo em vista que até 1973 o país titulara apenas cerca de 3.500 mestres e 500 doutores. Não menos ambiciosa era a Meta 2, que propunha a ampliação da capacidade de atendimento de 7.000 para 11.700 vagas anuais de mestrado e de 500 para 1.200 vagas 


\section{A GESTÃO DA PÓS-GRADUAÇÃO NO BRASIL ATRAVÉS DE SEUS PLANOS NACIONAIS: OS DESAFIOS DOS GESTORES DE CURSOS \\ DOI: http://dx.doi.org/10.5007/1983-4535.2012v5n4p43}

anuais de doutorado. Para atendimento das metas e implantação das mudanças, o governo propôs três programas interdependentes: (1) concessão de bolsas de estudo para alunos em tempo integral, (2) programas institucionais de capacitação de docentes e (3) admissão de docentes de maneira regular e programada pelas instituições. Determinava, ainda, o total de bolsas a serem concedidas pelas agencias federais (cerca de 59.650), o numero de docentes que iniciarão curso de mestrado e doutorado (12.000) e o número de novos docentes a serem admitidos por ano (2.000). Além disso, previa o total de recursos financeiros a ser despendido pelo governo federal nesses programas ${ }^{\mathrm{iii}}$, assim como as diferentes fontes e itens de despesa.

A análise do I PNPG é significativa, pois contextualiza os desafios do gestor de cursos de pós-graduação no início do estabelecimento dessas atividades no Brasil e nos ajuda a compreender melhor questões ainda presentes nos dias atuais. Ao longo do documento, foi possível observar a autonomia como uma característica muito forte dessas atividades, que começaram por iniciativa de docentes e com fontes diferenciadas de recursos. Os gestores dos cursos eram os próprios docentes e a autonomia lhes proporcionava independência e flexibilidade em relação ao governo e à universidade, o que resultava em "procedimentos administrativos próprios". Se, por um lado isso era positivo, por outro, não havia estabilidade nos cursos nem tampouco regulamentação, padronização ou qualquer parâmetro de avaliação dos mesmos. Subjazia ao I PNPG um tipo de racionalidade técnica que foi ao longo do tempo capilarizando a pós-graduação e as gestões dos programas. E mesmo tendo impulsionado o desenvolvimento e a qualidade desse nível de ensino, até hoje essa racionalidade encontra resistências nos gestores e docentes dos programas de pós-graduação, que iniciaram essas atividades de forma tão livre.

\section{Plano Nacional de Pós-Graduação (II PNPG - 1982/1985)}

O II Plano Nacional de Pós-Graduação foi implantado no início da década de 80, quando o país enfrentava um período de recessão derivado do enfraquecimento do modelo econômico do regime militar. Paralelamente, no plano político, o país atravessava o período de transição entre o regime autoritário e o regime democrático. João Figueiredo havia sido eleito pelo colégio eleitoral em 1978 e os sérios problemas econômicos, conflitos internos dentro das forças armadas e o excelente desempenho do único partido de oposição, o Movimento Democrático Brasileiro (MDB), primeiro nas eleições para prefeito e mais tarde para governador, fez com que o processo de abertura política fosse acelerado. Houve a 


\section{A GESTÃO DA PÓS-GRADUAÇÃO NO BRASIL ATRAVÉS DE SEUS PLANOS NACIONAIS: OS DESAFIOS DOS GESTORES DE CURSOS \\ DOI: http://dx.doi.org/10.5007/1983-4535.2012v5n4p43}

revogação do Ato Institucional 05 (1978), o Congresso aprovou a Anistia (1979) e uma nova lei partidária pôs fim ao bipartidarismo (1980).

O II PNPG manteve como objetivo da pós-graduação a formação de recursos humanos especializados para atendimento das demandas dos setores público e privado, mas focou as orientações na busca da qualidade, por meio de racionalização do uso dos recursos e do aprimoramento da avaliação (SANTOS e AZEVEDO, 2009). Ao comparar o II PNPG com o anterior, é possível perceber que o plano apresentado em 1982 foi bem mais modesto em seus objetivos e diretrizes, não apresentando nenhum programa governamental de apoio à pósgraduação ou meta de crescimento a ser alcançada. $\mathrm{O}$ caráter mais contido e menos interventor do II PNPG pode ser percebido ao longo de todo o texto, que se restringiu a apresentar um panorama da pós-graduação brasileira, explicitar as premissas básicas da política, o papel da pós-graduação no contexto nacional e definir objetivos, prioridades e diretrizes, sem determinar metas ou ações a serem realizadas. O foco de todo o documento foi a questão da qualidade, passando a mensagem de que era preciso tornar mais eficiente o sistema já existente.

Partindo da premissa de que o crescimento do número de pessoas altamente qualificadas viabilizaria o desenvolvimento científico, tecnológico e cultural brasileiro, o plano indicava que a consolidação da pós-graduação dependia de condições materiais e institucionais; de docentes e pesquisadores em condições adequadas de trabalho; da dinamização e desburocratização das instituições acadêmicas e da existência de fontes múltiplas de financiamento. Entretanto, observa-va problemas estruturais persistentes nos cursos stricto sensu, como a dependência de recursos extra-orçamentários, a instabilidade empregatícia, a irregularidade dos financiamentos, a escassez de técnicos e de pessoal de apoio, o número insatisfatório de professores para as atividades de pesquisa, ensino e orientação, entre outros.

De fato, apenas dois são os temas principais abordados ao longo do texto: flexibilidade e qualidade. A flexibilidade aparece no questionamento do "sentido absoluto e rígido" do binômio ensino-pesquisa e também dos cursos de mestrado e doutorado como o único mecanismo de capacitação e aperfeiçoamento do magistério, sob a alegação de que nem sempre a vinculação entre ensino e pesquisa se aplica a todos os âmbitos e que certas áreas do conhecimento têm "pouca afinidade" com a pós-graduação stricto sensu. Segundo o plano, eram igualmente importantes para a atualização do corpo docente os cursos de 


\section{A GESTÃO DA PÓS-GRADUAÇÃO NO BRASIL ATRAVÉS DE SEUS PLANOS NACIONAIS: OS DESAFIOS DOS GESTORES DE CURSOS \\ DOI: http://dx.doi.org/10.5007/1983-4535.2012v5n4p43}

aperfeiçoamento e especialização, a leitura dos periódicos especializados, a participação em eventos científicos e a elaboração de textos para publicação. Certamente, essa flexibilização da exigência de formação estava relacionada à conjuntura de crise econômica e escassez de recursos que o país atravessava.

Em congruência com esse contexto, também foi abordado o tema da qualidade que, segundo o texto, vinha diminuindo em função da expansão quantitativa do sistema. Assim, indicava-se a responsabilidade das instituições governamentais, especialmente as agências, de criar e manter condições essenciais para a produção acadêmica e cobrar sua efetiva realização. Naquele momento a avaliação dos cursos de pós-graduação realizada pela Capes, instituída desde 1976 como objetivo gerar parâmetros para orientar a distribuição de bolsas de estudo, ainda não tinha a dimensão dos dias atuais. Também foi sublinhada a necessidade de a pósgraduação formar profissionais, docentes e pesquisadores altamente qualificados, para implementar as diretrizes contidas no III Plano Nacional de Desenvolvimento e no III Plano Básico de Desenvolvimento Científico e Tecnológico.

Na penúltima sessão do plano, que tratava dos seus objetivos, foram definidas três prioridades: a busca da qualidade, a adequação do sistema às necessidades do país e a coordenação das ações das diferentes instancias governamentais. Para aumentar a qualidade do sistema de pós-graduação seria necessário fazer um acompanhamento mais eficaz dos recursos, aperfeiçoar os sistemas de informação e avaliação e apoiar o que for considerado "bom e promissor". Também seria preciso compatibilizar a pós-graduação e a pesquisa com as prioridades nacionais, e o MEC deveria zelar pela manutenção de um sistema de pósgraduação dinâmico e articulado. Por fim, ao estabelecer prioridades e diretrizes, o plano recomendava que o apoio dos órgãos governamentais fosse distribuído entre as diferentes áreas do conhecimento de forma distinta, de acordo com seu posicionamento no campo científico e com sua importância estratégica para o país.

De forma geral o II PNPG foca na questão da qualidade, apontando a necessidade de se aperfeiçoar os programas para um aproveitamento mais eficiente dos recursos. Aos gestores dos cursos de pós-graduação, ficou a incumbência de atender essa demanda, sob o risco de não se conseguirem verbas para a continuidade das atividades. 


\section{A GESTÃO DA PÓS-GRADUAÇÃO NO BRASIL ATRAVÉS DE SEUS PLANOS NACIONAIS: OS DESAFIOS DOS GESTORES DE CURSOS \\ DOI: http://dx.doi.org/10.5007/1983-4535.2012v5n4p43}

\section{Plano Nacional de Pós-Graduação (III PNPG - 1986/1989)}

O III Plano Nacional de Pós-Graduação foi publicado em 1986, no governo de José Sarney, quando o Brasil entrava na terceira etapa da transição democrática (KINZO, 2001), na qual os militares deixavam de deter o papel principal no processo, sendo substituídos pelos políticos civis e havendo também a participação dos setores organizados da sociedade. Sarney foi o primeiro presidente civil a chegar ao poder após o golpe militar de 1964. Em 1983, o PMDB iniciara uma tentativa de mudar as regras das eleições presidenciais, propondo uma emenda constitucional que restabelecesse o voto direto. A campanha das "Diretas Já", como ficou conhecida, contou com forte apoio popular, mas foi derrotada no Congresso. Em 1985, o colégio eleitoral elegeu como presidente da república o civil Tancredo Neves, candidato representante da oposição. Como este faleceu antes de tomar posse, Sarney assumiu a presidência com a incumbência de consolidar o processo de democratização brasileiro.

O lançamento do III PNPG, portanto, coincidiu com um momento em que novos arranjos institucionais eram pensados para o país e seu o foco principal foi o desenvolvimento da pesquisa pela universidade e a integração da pós-graduação ao Sistema de Nacional de Ciência e Tecnologia aliado ao setor produtivo nacional, pois naquele momento, sociedade e governo buscavam a independência econômica, científica e tecnológica para o Brasil.A Capes consultou a comunidade científica para a elaboração do documento, que expressava o desejo de conquista da autonomia nacional vigente no período.

A introdução do III PNPG aponta avanços conseguidos pela Política Nacional de PósGraduação, ao longo da década em que vigoram os dois primeiros planos (1975 -1985), entretanto, constata que seus objetivos centrais ainda não tinham sido plenamente alcançados, pois o Brasil não possuía cientistas em número adequado para a plena capacitação científica e tecnológica do país. Por isso, determinava, como objetivo principal, formar cientistas em quantidade, qualidade e perfil adequados ao modelo de desenvolvimento do país, acrescentando, aos objetivos dos planos anteriores, de forma enfática, a necessidade de institucionalização e ampliação da pesquisa nas universidades e a integração da pósgraduação ao Sistema Nacional de Ciência e Tecnologia e ao setor produtivo.

Assim como nos planos anteriores, no III PNPG também foi feita uma análise da evolução e situação atual da pós-graduação, na qual se constatou uma significativa evolução da pós-graduação no período 1975-1985, tanto em termos quantitativos, como em termos qualitativos, e a permanência de problemas como: baixa produtividade, heterogeneidade em 


\section{A GESTÃO DA PÓS-GRADUAÇÃO NO BRASIL ATRAVÉS DE SEUS PLANOS NACIONAIS: OS DESAFIOS DOS GESTORES DE CURSOS \\ DOI: http://dx.doi.org/10.5007/1983-4535.2012v5n4p43}

relação a áreas de conhecimento e regiões do país, carência de pesquisadores com formação interdisciplinar, elevado tempo médio de titulação, entre outros. Observou-se também que as atividades de pesquisa e a pós-graduação ainda não haviam sido plenamente institucionalizadas e careciam disso para assegurar seu desenvolvimento. O plano indicava a necessidade de definição de atribuições no âmbito do governamental em relação à coordenação e fomento dessas atividades, tornando os processos de financiamento eficientes e desburocratizados e havendo maior articulação entre as atividades de pós-graduação com a graduação, a pesquisa, o setor produtivo e as próprias instituições de pesquisa e ensino. Outro problema apontado foi a discrepância entre as atividades de pós-graduação nas diferentes regiões do país, com a Região Norte respondendo por apenas formação de $0,85 \%$ desse nível de ensino e a Região Sudeste por 74,21\%.

Após a análise da conjuntura em que se encontrava a pesquisa e a pós-graduação, o plano apresenta uma ordem de medidas e providencias a serem tomadas para a expansão da base científica nacional: manutenção da qualidade dos cursos bons e excelentes, investimentos para melhoria da produtividade, consolidação e aperfeiçoamento dos cursos com problemas, estímulo à abertura de doutorado nos programas de mestrado, criação de novos programas de mestrado, aperfeiçoamento e expansão do sistema de bolsas de estudo, fomento à capacitação no exterior e melhoria de infraestrutura para as atividades de pósgraduação nas universidades. Foram eleitas como diretrizes gerais do documento: estimular as atividades de investigação científica e tecnológica; consolidar as instituições universitárias e de pós-graduação; assegurar recursos para infraestrutura e financiamento de projetos de pesquisa; garantir a participação da comunidade científica na coordenação, no planejamento e na execução das atividades de pós-graduação; estimular a diversidade de concepções e organizações e; assegurar condições ao estudante-bolsista se dedicar integralmente à pósgraduação.

Diante das metas e diretrizes apresentadas, é possível observar que a proposta do III PNPG difere significativamente da proposta apresentada no II PNPG, pois enquanto o documento de 1982, num tom mais refreado, focava na questão da qualidade, na otimização da estrutura já existente e na flexibilização das possibilidades de formação; o documento de 1986, num tom mais propositivo, deixava clara a necessidade de institucionalização da pesquisa e da pós-graduação nas universidades, de investimentos e de expansão do sistema como um todo. Paralelamente, reconhecia também a necessidade de assegurar a participação 


\section{A GESTÃO DA PÓS-GRADUAÇÃO NO BRASIL ATRAVÉS DE SEUS PLANOS NACIONAIS: OS DESAFIOS DOS GESTORES DE CURSOS \\ DOI: http://dx.doi.org/10.5007/1983-4535.2012v5n4p43}

da comunidade científica nos diferentes âmbitos da pós-graduação.Essa diferença entre os dois planos nos leva a deduzir que a conjuntura nacional se tornava mais otimista na segunda metade da década de 80, com o avanço da transição democrática e o desejo de construção de um novo modelo de país, no qual a pós-graduação cumpriria um importante papel de formação de recursos humanos para o desenvolvimento científico e tecnológico ${ }^{1 \mathrm{iv}}$.

Ainda nessa linha propositiva, o III PNPG trás um tópico destinado apenas às estratégias a serem seguidas pelos vários órgãos e instituição que compõem o sistema de pósgraduação para o alcance dos objetivos apresentados, entre as quais se destacam o aperfeiçoamento do sistema de avaliação da pós-graduação e avaliação das ações de fomento; a promoção de maior interação entre graduação/pós-graduação/programas e centros de pesquisa; melhoria do financiamento de bolsas, revistas científicas e aquisição de periódicos; e também apoio aos grupos emergentes de pesquisa, aos mestrados de bom nível, à criação de cursos de doutorado e de novos programas, e à formação de recursos humanos na Amazônia.

Nesse tópico, o documento trata também de questões mais fortemente relacionadas ao trabalho dos gestores das instituições, indicando medidas específicas para a institucionalização da pesquisa nas universidades, a saber: destacar, nos orçamentos das instituições, verbas para a pós-graduação; reestruturar a carreira docente no sentido de valorizar a produção científica; planejar a ampliação dos quadros universitários; institucionalizar a atividade sabática; e, estimular a autoavaliação dos cursos. Trata-se de incumbências que precisam ser realizadas no interior das universidades e sobre as quais os gestores de programas de pós-graduação têm um papel importante. Embora eles não tenham poder de decisão exclusivo sobre orçamentos institucionais ou ampliações de quadros docentes, devido ao processo de democratização, cada vez mais serão abertos espaços para a participação da comunidade acadêmica em conselhos e comissões, e estes, por sua vez, terão maior influencia em relação aos rumos da universidade. Diante desse quadro, a atividade de coordenação de cursos ou programas de pós-graduação vai ganhando mais complexidade.

\section{Plano Nacional de Pós-Graduação (IV PNPG - plano não oficializado)}

Após o III PNPG, que tinha previsão de vigorar de 1986 a 1989, deveria ter sido elaborado o IV Plano Nacional de Pós-Graduação. Porém, ao longo dos anos 90 e até meados dos anos 2000, não houve formalização de um novo plano nos moldes dos anteriores. A 


\section{A GESTÃO DA PÓS-GRADUAÇÃO NO BRASIL ATRAVÉS DE SEUS PLANOS NACIONAIS: OS DESAFIOS DOS GESTORES DE CURSOS \\ DOI: http://dx.doi.org/10.5007/1983-4535.2012v5n4p43}

despeito disso, a pós-graduação brasileira atravessou um período de mudanças significativas em suas políticas, influenciada pelo contexto de Reforma do Estado Brasileiro.

Com a redemocratização, o Brasil recuperou suas bases federativas e, ao longo dos anos 90, implantou um extensivo programa de descentralização, visto com bons olhos pela população, pelos movimentos sociais, pelos organismos internacionais e pelo governo(BASTOS, 1999; CASTRO e MENEZES, 2002), pois processos de recuperação do federalismo e de promoção da descentralização resultaram de um mesmo movimento histórico - a negação do autoritarismo e da centralização deixada pela ditadura militar.Somado a isso, ao longo dos governos dos presidentes Fernando Collor de Melo (1990-1992), Itamar Franco (1992-1995) e Fernando Henrique Cardoso (1995- 1999/ 1999-2002), em virtude do contexto internacional de globalização e neoliberalismo, também ganhou força um discurso que defendia que o problema da educação não era de ordem quantitativa (de vagas, recursos etc.), mas sim, de ordem qualitativa (má aplicação dos recursos financeiros, ineficiência dos recursos humanos etc.), e que propunha a diminuição da intervenção estatal em diversos setores, com aumento da agilidade e eficiência do Estado, através do controle público, entre outras medidas (CASTRO e MENEZES, 2002).

Ao longo da década de 90, portanto, essas iniciativas começaram a ser implementadas, possibilitando o processo de Reforma do Estado no Brasil, que tinha como características a descentralização da administração e a instalação de mecanismos de controle. No que se refere às políticas educacionais, houve fortalecimento de diretrizes relacionadas à gestão democrática, à descentralização de recursos, autonomia dos gestores e avaliação do ensino. A partir dessas mudanças, gestores educacionais da educação básica até a pós-graduação, começaram administrar novos recursos, assumir novas responsabilidades e lidar crescentemente com questões relacionadas à descentralização administrativa, financeira e pedagógica da educação.

No âmbito da pós-graduação, ao longo dos anos 90, a Capes promoveu discussões para a construção do IV PNPG. A Comissão Mista Capes/CNPq (2004) ${ }^{\mathrm{v}}$, que elaborou documento preliminar para a construção do V PNPG, apontou os principais acontecimentos articulados pela Capes em torno da elaboração do IV PNPG: distribuição ajunto à comunidade acadêmica do documento Discussão da Pós-Graduação Brasileira ${ }^{v i}$ (1996), realização de um Seminário Nacional para discussão das propostas (1996), edição especial do INFOCAPES ${ }^{\text {vii }}$ com sínteses dos relatores do seminário, recebimento do Documento Final 


\section{A GESTÃO DA PÓS-GRADUAÇÃO NO BRASIL ATRAVÉS DE SEUS PLANOS NACIONAIS: OS DESAFIOS DOS GESTORES DE CURSOS \\ DOI: http://dx.doi.org/10.5007/1983-4535.2012v5n4p43}

consolidado (1997), seminário Pós-Graduação: enfrentando novos desafios (2000) e resultados do Seminário de 2000 publicados em número especial do INFOCAPES (2001). As discussões realizadas nesses encontros e as publicações resultantes deles se constituíram no espaço em que a pós-graduação foi pensada nos anos em que não houve um PNPG vigorando.

A maior parte dos debates ocorreu durante os governos de Fernando Henrique Cardoso e girou em torno de dois princípios básicos: autonomia institucional e flexibilização. Esses princípios estavam alinhados com o contexto político da reforma, que defendia a descentralização e diminuição da participação da União na gestão do ensino, e indicava que a universidade deveria assumir a responsabilidade pela gestão de seu sistema de pós-graduação (SANTOS e AZEVEDO: 2009). A flexibilização era identificada na preocupação com o tempo de titulação do aluno e apoio a novos tipos de mestrados, como os interdisciplinares e os profissionalizantes. Documentos gerados ao longo do processo apontaram lacunas no sistema, entre as quais, destacavam-se: a perda de quadros atuantes da pós-graduação, a infraestrutura insuficiente e a permanência do desequilíbrio da oferta de cursos entre as regiões brasileiras e entre as diferentes áreas do conhecimento. (ibidem, 2009; BRASIL, 2010).

O governo do Presidente Fernando Henrique Cardoso elegia o descontrole inflacionário como o maior entrave ao crescimento econômico e apontava, como solução para tal problema, a articulação do Brasil à economia internacional globalizada, através do fortalecimento do poder decisório do país e do desenvolvimento científico e tecnológico. A educação foi incluída como uma das cinco metas prioritárias do seu governo, pois seria um dos pré-requisitos para a adequada capacitação dos recursos humanos brasileiros (CASTRO e MENEZES, 2002), havendo valorização do papel da pós-graduação nessa tarefa. Assim, num período em que não houve vigência formal de um PNPG, muitas ações foram implantadas pela Capes para acelerar a formação de recursos humanos de alto nível no país. Entre elas, cabe destacar: a instituição de comissão de bolsas para estabelecer os critérios de concessão e acompanhar o desempenho do bolsista; a determinação de um prazo máximo de vigência da bolsa e a inclusão de um tempo médio de titulação na avaliação; regulamentação dos mestrados profissionais, novas formatações de cursos de pós-graduação (cursos em rede ou em caráter interinstitucional), ampliação da cooperação internacional, criação do Portal de Periódicos da Capes, entre outras (SANTANA e MARTINS, 2012). Foi ainda nesse período que a Capes formulou um novo paradigma de avaliação, introduzido para o biênio 1996/1997, 


\section{A GESTÃO DA PÓS-GRADUAÇÃO NO BRASIL ATRAVÉS DE SEUS PLANOS NACIONAIS: OS DESAFIOS DOS GESTORES DE CURSOS \\ DOI: http://dx.doi.org/10.5007/1983-4535.2012v5n4p43}

no qual o foco da política deixou de ser a docência e passou a ser a pesquisa e a produção científica. Para os gestores de cursos de pós-graduação foi um período que, embora sem a vigência formal de Plano de Pós-Graduação, mudanças importantes ocorreram e foi necessário adaptar-se ao novo contexto.

\section{Plano Nacional de Pós-Graduação (V PNPG - 2005/2010)}

Luiz Inácio Lula da Silva foi eleito presidente do Brasil pelo Partido dos Trabalhadores e, em 2003, iniciou um governo no qual deu seguimento à política econômica de estabilidade conquistada pelo presidente de Fernando Henrique Cardoso (FHC), buscando aliá-la à retomada do crescimento do país, à redução da pobreza e à diminuição da desigualdade social.

Em seu primeiro ano de governo, Lula instituiu um Grupo de Trabalho Interministerial $(G T I)^{\text {viii }}$ encarregado de analisar a situação das Instituições Federais de Ensino Superior (IFES) e apresentar um plano de ação visando à reestruturação, ao desenvolvimento e à democratização das mesmas. O relatório foi divulgado em dezembro do mesmo ano, com o objetivo de oferecer diretrizes gerais para a realização de uma Reforma Universitária Brasileira, que apontou duas linhas de ação imediata: o Pacto da Educação Superior para o Desenvolvimento Inclusivo, que garantiria um fluxo adicional de recursos para as instituições (inclusive particulares) que aderissem ao programa, cujo objetivo era induzir a formação em áreas estratégicas como engenharia, saúde, educação, biologia, licenciatura para ensino básico, produção alimentar e gestão de políticas; e a ampliação da Educação a Distância, entendida como um caminho viável e necessário em um país com as dimensões continentais como o Brasil.

Os fundamentos da reforma realizada no governo Lula foram questionados por diversos críticos, que alegavam que seus verdadeiros preceitos eram: investimento mínimo na educação básica; diversificação das fontes de financiamento da educação superior; abertura do setor educacional para a participação das empresas e grupos estrangeiros, através da educação superior à distância; restrição da autonomia das universidades públicas apenas à liberdade de captar recursos financeiros; condicionamento do repasse de recursos ao desempenho, entre outros (LIMA, 2004; OTRANTO, 2006; TRÓPIA, 2007). A despeito das críticas recebidas, o governo Lula deu seguimento a diferentes ações políticas em consonância com as diretrizes pensadas para a Reforma Universitária. Entre as principais ações, podemos destacar: o 


\section{A GESTÃO DA PÓS-GRADUAÇÃO NO BRASIL ATRAVÉS DE SEUS PLANOS NACIONAIS: OS DESAFIOS DOS GESTORES DE CURSOS \\ DOI: http://dx.doi.org/10.5007/1983-4535.2012v5n4p43}

Sistema Nacional de Avaliação da Educação Superior (SINAES) ${ }^{\mathrm{ix}}$; as Parcerias PúblicoPrivadas $(\mathrm{PPP})^{\mathrm{x}}$, o Programa Universidade para Todos (PROUNI) ${ }^{\mathrm{xi}}$, a Lei de Inovação Tecnológica; a instituição da Educação à Distância ${ }^{\text {xii }}$, a Universidade Aberta do Brasil (UAB) xiii, o Programa de Apoio ao Plano de Reestruturação e Expansão das Universidades Federais (REUNI) ${ }^{\text {xiv }}$, O Plano de Desenvolvimento da Educação; e o Banco de professoresequivalente $^{\mathrm{xv}}$.

Em relação à pós-graduação, ainda em março de 2003, Lula nomeara a Comissão Mista CAPES/CNPq para o Desenvolvimento da Pós-Graduação e da Ciência e Tecnologia ${ }^{\text {xvi }}$, que elaborou o documento que serviu de base para a elaboração do V Plano Nacional de PósGraduação (V PNPG), que vigorou de 2005 a 2010. Neste plano, a Capes aponta como objetivo fundamental o crescimento equânime do Sistema Nacional de Pós-Graduação, sublinhando o papel do Estado como principal responsável pelo seu financiamento.

A análise da situação da pós-graduação começa com uma retrospectiva das políticas desse nível de ensino através dos planos nacionais, concluindo que o conjunto de planos e as ações implementadas a partir das orientações dos PNPG permitiram o desenvolvimento da pós-graduação no país. $\mathrm{O}$ plano também expõe suas bases legais, apontando a responsabilidade da União em relação a esse nível de ensino e concluindo que cabe à Capes coordenar a política do sistema nacional de pós-graduação, exercendo função normalizadora e avaliadora, garantindo um padrão nacional de excelência e de qualidade dos diplomas. Aqui, é importante observar que, num tom diferente do relatório do GT sobre ensino superior, os autores do V PNPG fizeram questão de frisar a responsabilidade da União em relação à pósgraduação, exercendo papel de promoção, articulação, organização e avaliação desse nível de ensino, e garantindo seu padrão de qualidade. Mais a frente, veremos que também serão assinaladas responsabilidades orçamentárias para se atingir esse padrão.

O texto faz indicações sobre o sistema educacional brasileiro e sublinha a importância de uma educação básica forte, qualificada, equânime e democrática para que exista uma pósgraduação consequente com o princípio da igualdade de oportunidades. Pela primeira vez um PNPG indica a responsabilidade da pós-graduação em relação à educação básica e à formação de seus docentes e marca uma mudança importante em termos de objetivos do sistema de pós e também de responsabilidades da Capes. Em seguida, é demonstrado através de dados que o sistema cresceu em número de cursos, número de alunos matriculados e titulados, em todas as regiões do país e em todas as áreas de conhecimento. O número de bolsas também cresceu, 


\section{A GESTÃO DA PÓS-GRADUAÇÃO NO BRASIL ATRAVÉS DE SEUS PLANOS NACIONAIS: OS DESAFIOS DOS GESTORES DE CURSOS \\ DOI: http://dx.doi.org/10.5007/1983-4535.2012v5n4p43}

mas em ritmo mais lento. Todavia, os desequilíbrios regionais persistem e nosso sistema ainda é pequeno quando comparado a países desenvolvidos e países competidores em áreas da política industrial brasileira ${ }^{\text {xvii }}$.Em seguida, alerta-se para o fato de que o desenvolvimento científico é um fator determinante na geração de renda e na promoção do bem-estar social de uma nação e que a pós-graduação brasileira é a base para a formação de recursos humanos necessários ao desenvolvimento da ciência e tecnologia no país e tem contribuído de forma decisiva nesse processo.

Entretanto, ainda existem problemas como a carência de uma política nacional de pósgraduação que supere as disparidades de desenvolvimento entre os Estados, a necessidade de inserir a política de formação de recursos humanos no contexto da política industrial brasileira, especialmente em setores estratégicos. Assim, as principais debilidades apontadas foram: falta de planejamento para orientar o crescimento organizado do sistema; assimetrias regionais e estaduais; descompasso entre matrículas x titulações x bolsas; número insuficiente de programas no Norte, Nordeste e Centro-Oeste; pouca articulação entre as agências federais de fomento, baixa prioridade concedida aos doutores na admissão aos quadros docentes das IES; e reduzida disponibilidade de recursos financeiros para capacitação docente.

Quanto à primeira crítica, falta de planejamento para orientar o crescimento organizado do sistema, há que se fazer uma ressalva. Desde o primeiro plano a questão das assimetrias regionais e entre áreas de conhecimento é constatada e são apresentadas diretrizes visando sua superação, embora o problema persista. Talvez a questão não esteja tanto na falta de planejamento ou orientação para o crescimento, mas sim na dificuldade de efetivar ações concretas para sua superação. Mestres e doutores formados em regiões centrais têm pouco interesse em atuar em regiões mais periféricas, assim como as propostas de cursos novos são mais abundantes onde existem mais centros de excelência e maior disponibilidade de pessoal especializado. Levando-se ainda em conta que não há grandes incentivos financeiros para os profissionais se interiorizarem, visto que os rendimentos dos professores das universidades públicas são padronizados em um único plano de carreiras, o problema das assimetrias tornase mesmo uma questão de difícil resolução.

Diante disso, é definido como objetivo principal do V PNPG o crescimento equânime do sistema nacional de pós-graduação, visando o desenvolvimento científico, tecnológico, econômico e social do país, por meio de seis principais diretrizes: estabilidade e indução, estratégias para melhoria do sistema, financiamento e sustentabilidade, novos modelos, 


\section{A GESTÃO DA PÓS-GRADUAÇÃO NO BRASIL ATRAVÉS DE SEUS PLANOS NACIONAIS: OS DESAFIOS DOS GESTORES DE CURSOS \\ DOI: http://dx.doi.org/10.5007/1983-4535.2012v5n4p43}

políticas de cooperação internacional e de formação de recursos humanos no exterior e, avaliação e qualidade. A estabilidade refere-se à manutenção do ritmo de crescimento do sistema e a indução visa reduzir as diferenças regionais, intra-regionais e entre estados. A primeira estratégia apontada para a melhoria do desempenho do sistema foi a elaboração de programas específicos objetivando solucionar diferentes tipos de assimetrias pelas agencias de fomento, em articulação com os governos estaduais, o setor empresarial e os fundos setoriais. Em relação à estratégia de financiamento e sustentabilidade, o documento recorre à Constituição para afirmar que cabe ao Estado um papel preponderante no financiamento da pós-graduação, complementando que a eficácia dos investimentos só é obtida pela continuidade dos programas e normas.

Também foi sugerida a diversificação do sistema, com novos modelos para a pósgraduação, que sejam capazes de cumprir o desafio de fortalecer nossas bases científicas, formar docentes para todos os níveis de ensino e também quadros para âmbitos não acadêmicos, buscando equilíbrio em todas as regiões do país. Para isso, seria necessário redefinir o papel do mestrado, fomentar programas de cooperação interinstitucional, expandir um programa de bolsa para estágio no Brasil, incentivar novos projetos de educação à distancia em áreas estratégicas e para formação qualificada de docentes em atuação. E ainda são indicadas políticas de cooperação internacional e de formação de recursos humanos no exterior.

Aqui cabe um parêntese para observar que esta é uma parte do V PNPG bastante relacionada aos gestores de programas de pós-graduação. Ao sugerir a diversificação do sistema através de novos modelos, o governo indica que está disposto a acolher projetos fora das linhas tradicionais de programas com mestrado e doutorado apresentados até então, comomestrados profissionalizantes, cooperações institucionais, e experiências com educação à distancia.

Por fim, aponta-se que a avaliação deve ser baseada na qualidade e excelência de resultados, dando ênfase à produtividade dos docentes e discentes e à produção científica e tecnológica dos laboratórios ou grupos de pesquisa que compõem a pós-graduação. Cabe destacar que nesse item há sugestão de diversificação do sistema de avaliação e introdução de processos de avaliação qualitativa dos produtos dos programas, como livros, patentes e tecnologias. Em relação à avaliação, embora não esteja no texto de forma explícita, também é importante frisar o papel dos gestores de programas de pós-graduação. Diante das exigências 


\section{A GESTÃO DA PÓS-GRADUAÇÃO NO BRASIL ATRAVÉS DE SEUS PLANOS NACIONAIS: OS DESAFIOS DOS GESTORES DE CURSOS \\ DOI: http://dx.doi.org/10.5007/1983-4535.2012v5n4p43}

cada vez mais específicas em relação à produção dos programas e do peso da avaliação da Capes na trajetória dos mesmos, a avaliação torna-se um elemento norteador do trabalho de gestão nos cursos de mestrado e doutorado.

Em seguida, o V PNPG trás uma seção em que calcula três diferentes cenários de crescimento para a pós-graduação, baseado nas séries históricas existentes. O exercício é importante, pois permite aos gestores trabalharem com números concretos e aproximados em suas projeções. Baseados na combinação dos três cenários, apresentam as metas e o orçamento necessário para a implementação do PNPG no período de 2005-2010. Primeiramente, é apontada a necessidade de uma ação indutiva para a pós-graduação nas regiões Norte, Nordeste e Centro-oeste, por meio do aumento do investimento e do número de professores. Propõe-se que, para essas regiões, as parcelas percentuais do acréscimo de orçamento previsto para a expansão do sistema seja diretamente proporcional ao número de docentes. O mesmo esforço está previsto em relação à superação das assimetrias intraregionais. Determina ainda que, em 2010, o Brasil esteja formando mais de 16.000 doutores e 45.000 mestres, com uma taxa de acréscimo no número de titulados de 108\% em Engenharias \& Ciências da Computação e $82 \%$ em Ciências Agrárias. Em relação ao orçamento para o período, prevê-se que serão necessários $\mathrm{R} \$ 3,26$ bilhões de reais, distribuídos ao longo de seis anos.

Diante dos números apresentados em relação às metas e orçamento da pós-graduação, é possível observar que há uma diferença no papel dado à União em relação à pós=graduação e ao ensino superior. $\mathrm{O}$ documento norteador da política para o ensino superior aponta como principais saídas para a crise no sistema: a autonomia das universidades para aumentar a captação de recursos externos, o incentivo financeiro para que instituições privadas colaborem com o objetivo de formar profissionais em áreas estratégicas, a educação a distancia como único caminho viável para alcançar as metas de formação almejadas e o reforço ao papel do Estado como regulador do sistema, cabendo às IES prestarem contas ao MEC apenas no que se refere ao "produto obtido". No nível da pós-graduação, por sua vez, o V PNPG aponta a responsabilidade da União em relação à coordenação, promoção, articulação e avaliação desse nível de ensino através da Capes e ainda o financiamento desse sistema, prevendo aumentos significativos no orçamento destinado a bolsas, programas e capacitação de docentes com recursos do Tesouro Nacional. A parceria com as empresas foi mencionada em relação a programas estratégicos específicos, mesmo assim, o documento aponta que eles deveriam ser 


\section{A GESTÃO DA PÓS-GRADUAÇÃO NO BRASIL ATRAVÉS DE SEUS PLANOS NACIONAIS: OS DESAFIOS DOS GESTORES DE CURSOS \\ DOI: http://dx.doi.org/10.5007/1983-4535.2012v5n4p43}

amparados por novos orçamentos. Também não há menção a incentivos para que as instituições de ensino superior privadas assumam ou mesmo aumentem os números de cursos stricto sensu.O texto ainda sinaliza e destaca o papel das agencias em relação à pósgraduação, assim como das Secretarias Estaduais de Ciência e Tecnologia e fundações de apoio, especialmente a FINEP, por ser gestora dos fundos setoriais. Também menciona as empresas estatais como um importante apoio no próprio financiamento da pós-graduação nacional. O Estado, portanto, está presente em todas as opções de financiamento da pósgraduação.

Outra diferença observada em relação às propostas para nível superior e pós-graduação é o papel da Educação a Distância $(\mathrm{EaD})$. Essa modalidade de ensino é fortemente estimulada para a graduação no primeiro documento, que indica que sem ela, inclusive, o país “(...) não teria condições de aumentar as vagas de forma maciça no curto e médio prazo." (BRASIL, 2003, p. 13) Enquanto isso, em relação à pós-graduação, o V PNPG menciona a EaD apenas em duas oportunidades: primeiramente, indicando que as agencias devem incentivar projetos de $\mathrm{EaD}$ com propostas inovadoras e em áreas estratégicas e, depois, como proposta para a formação de corpo docente da educação básica. As duas menções aparecem na seção de diretrizes gerais do PNPG, no item Novos Modelos (4.4), todavia, o crescimento da EaD não é especificado nos cenários de crescimento ou nas metas e orçamento. Assim, é possível observar que a educação a distancia não é vista como "a" solução para os problemas de expansão da pós-graduação.

Também é possível supor que havia um entendimento por parte do governo de que o Estado é o principal responsável pela pós-graduação e que deve arcar com seus custos, provavelmente por entender esse nível de ensino como essencial para o desenvolvimento científico e tecnológico do país, conforme mencionado no item referente a diagnóstico e análise da PG. Isto não significa, entretanto, que o Estado desconsiderava a importância do nível superior para o desenvolvimento da nação, mas, talvez, que os planejadores das políticas públicas do governo Lula entendessem que seria possível abrir a graduação para investimentos da iniciativa privada e que o controle da qualidade do ensino ofertado seria exercido através de um forte sistema de avaliação.

A avaliação também tem papel de destaque na pós-graduação, pois o V PNPG a relaciona diretamente à qualidade e excelência de resultados dos programas, indicando a necessidade de preservação e fortalecimento do sistema, da periodicidade das avaliações e 


\section{A GESTÃO DA PÓS-GRADUAÇÃO NO BRASIL ATRAVÉS DE SEUS PLANOS NACIONAIS: OS DESAFIOS DOS GESTORES DE CURSOS \\ DOI: http://dx.doi.org/10.5007/1983-4535.2012v5n4p43}

considerando o impacto de sua produção científica e tecnológica para o setor econômico, industrial e social. Um aspecto importante das diretrizes pensadas para o período 2005-2010, especialmente para os programas da área da educação, é que houve a previsão de introduzir no sistema processos de avaliação qualitativa dos produtos dos programas de doutorado e mestrado. Com isso, previu-se a inclusão de produtos até então subavaliados, como os livros, patentes e tecnologias e o destino dos egressos; importantes, respectivamente, nas áreas de Humanidades, Ciência e Tecnologia, e no caso dos Mestrados Profissionais.

\section{CONSIDERAÇÕES FINAIS}

Ao longo do artigo foi possível observar que, desde o I até o V PNPG, os diferentes tempos de vigência, assim como os tópicos abordados em cada um dos planos variaram em função do contexto histórico em que cada um dos documentos foi gerado e vigorou. Essas diferenças foram detalhadas ao longo do artigo e buscamos observar, especificamente, como elas influenciaram o papel dos gestores de programas de pós-graduação.

No I PNPG, lançado no período de enfraquecimento do regime militar, fica clara a intenção do governo de coordenar e controlar melhor as atividades de pós-graduação, determinando fontes de financiamento, atribuições aos diferentes entes do sistema, metas a serem alcançadas e a necessidade de avaliação. Isso fez com que os gestores, que até então gozavam de bastante independência e autonomia em relação à administração dos programas, tivessem que se adequar a uma estrutura hierárquica coordenada pela esfera federal.

O II PNPG, por sua vez, refletiu o momento político e econômico de transição democrática e crise financeira e limitou-se a orientar as atividades desse nível de ensino no sentido de otimizar os recursos existentes, melhorar a qualidade e flexibilizar as possibilidades de formação. Para os gestores, a principal mensagem é que deveriam contribuir para a melhoria da qualidade dos programas, aproveitando de forma mais eficiente os recursos, sob pena de não conseguir verbas para a continuidade das atividades.

Com o avanço da redemocratização e o desenho de novas configurações institucionais no país, o III PNPG teve como objetivo principal institucionalizar e ampliar as atividades de pesquisa e pós-graduação. Coube aos gestores de cursos, através da participação nos processos decisórios, contribuir para: destacar, no orçamento das instituições, verbas para a pós-graduação; valorizar a produção científica na carreira docente; pensar a ampliação dos 


\section{A GESTÃO DA PÓS-GRADUAÇÃO NO BRASIL ATRAVÉS DE SEUS PLANOS NACIONAIS: OS DESAFIOS DOS GESTORES DE CURSOS \\ DOI: http://dx.doi.org/10.5007/1983-4535.2012v5n4p43}

quadros com a absorção de egressos; institucionalizar a atividade sabática; e realizar a autoavaliação dos cursos.

O IV PNPG não chegou a ser publicado, mas de acordo com o contexto político de descentralização e diminuição da participação da União na gestão do ensino, grandes mudanças foram introduzidas na pós-graduação no período, às quais a pós-graduação e especificamente os gestores de programa tiveram que se adaptar, como: novo modelo de avaliação de programas pela Capes com foco na pesquisa e produção científica, flexibilização em relação ao tempo de titulação e apoio a novas modalidades de curso; descentralização e diminuição da participação da União na gestão do ensino.

O V PNPG foi lançado no governo Lula, durante o qual se implantou uma Reforma do Ensino Superior, baseada na autonomia das universidades para a captação de recursos externos, no incentivo financeiro para instituições privadas formarem profissionais em áreas estratégicas, na educação à distancia como único caminho viável para alcançar as metas de formação e no reforço ao papel do Estado como regulador do sistema. No âmbito da pósgraduação, em contrapartida, foi reafirmado o papel do Estado como principal financiador do sistema, sendo a Capes responsável por sua coordenação, articulação e avaliação. A EaD é vista como uma das possibilidades estratégicas e não há menção a incentivos para instituições particulares assumirem esse nível de ensino. Diante da necessidade de fortalecer nossas bases científicas, formar docentes para todos os níveis de ensino e quadros para mercados não acadêmicos, a sugestão foi a diversificação do sistema através da proposição de novos modelos (mestrado profissional, experiências com Ead e cooperações institucionais). Aos gestores cabe atender a essa demanda de diversificação e ter atenção cada vez maior aos parâmetros de avaliação da Capes.

Somaram-se demandas de regulamentação e padronização das atividades de pós-graduação (I PNPG), de melhoria da qualidade dos cursos (II PNPG), desenvolvimento da pesquisa na universidade (III PNPG), descentralização da gestão e adequação ao novo modelo de avaliação de cursos (IV PNPG) e de diversificação do sistema através da proposição de novos modelos (V PNPG). Diante disso, a autonomia administrativa e pedagógica que os gestores e docentes de cursos stricto sensu gozavam no início da pós-gradaução no país ficou cada vez mais reduzida, seja por conta das avaliações da Capes, seja pela necessidade de atender cada vez mais demandas, seja pela necessidade de submissão de projetos a diferentes editais para 
arrecadação de recursos para os programas ou mesmo pelas contingências de uma vida institucional mais democrática e, por consequência, mais "compartilhada".

Coube aos gestores e docentes desse nível de ensino um esforço cada vez maior para a adaptação aos novos contextos. Inegável reconhecer, entretanto, que esses fatores foram fundamentais para o desenvolvimento da pós-graduação brasileira e foram decisivos para seu crescimento e qualidade. As mudanças introduzidas pelos sucessivos planos e pela avaliação dos programas impulsionaram esse nível de ensino que vem sendo uma etapa cada vez mais vigorosa no país, tanto em termos de resultados quantitativos, com o aumento do número de cursos e alunos, como qualitativos, com avanços científicos em diferentes áreas do conhecimento e reconhecimento internacional.

\section{REFERÊNCIAS E CITAÇÕES}

BRASIL. Grupo de Trabalho Interministerial. Bases para o enfrentamento da crise emergencial das universidades federais e roteiro para a Reforma Universitária brasileira. Brasília: 15 de dezembro de 2003. (mimeo).

BRASIL. Ministério da Educação. Coordenação de Aperfeiçoamento de Pessoal de Nível Superior. Plano Nacional de Pós-Graduação - PNPG 2005/2010. Brasília, DF. 2004.

BRASIL. Ministério da Educação e Ministério do Planejamento, Orçamento e Gestão. Portaria Normativa Interministerial, $\mathbf{n}^{\mathbf{0} 22}$, de 30 de abril de 2007.

BRASIL. Ministério da Educação. Coordenação de Aperfeiçoamento de Pessoal de Nível Superior. Plano Nacional de Pós-Graduação - PNPG 2011/2020. Brasília, DF. 2010.

LIMA, K. Reforma da educação superior do governo Lula e educação à distância: democratização ou subordinação das instituições de ensino superior à ordem do capital? In: 27a. Reunião Anual da ANPEd Sociedade, democracia e educação: qual universidade? 2004, Caxambu - MG. Anais da 27 Reunião Anual da ANPEd, 2004.

MARTINS, C. E. O Brasil e a dimensão econômico-social do governo Lula: resultados e perspectivas.Rev. Katálysis, Jun. 2007, vol.10, no. 1, p.35-43. ISSN 1414-4980

OTRANTO, R. C. A Reforma da Educação Superior do Governo Lula: da inspiração à implantação. In: João dos Reis da Silva Jr; João Ferreira de Oliveira; Deise Mancebo. (Org.). Reforma Universitária: dimensões e perspectivas. Reforma Universitária: dimensões e perspectivas. 1ed. Campinas, SP: Alínea, 2006, v. 1, p. 43-58.

TRÓPIA, P. V. A política para o ensino superior do governo Lula: uma análise crítica. Cadernos da pedagogia (UFSCar. Online), v. 1, p. 1-19, 2007.

BASTOS, João Batista. Gestão Democrática. Rio de Janeiro: DP\& A: SEPE, 1999. 
BRASIL. Ministério da Educação e Cultura. Conselho Nacional de Pós-Graduação. I Plano Nacional de Pós-Graduação. Brasília, DF, 1974. In: BRASIL. Ministério da Educação. Coordenação de Aperfeiçoamento de Pessoal de Nível Superior. Plano Nacional de PósGraduação - PNPG 2005/2010. Brasília, DF. 2004.

BRASIL. Ministério da Educação e Cultura. Conselho Nacional de Pós-Graduação. II Plano Nacional de Pós-Graduação. Brasília, DF, 1982. In: BRASIL. Ministério da Educação. Coordenação de Aperfeiçoamento de Pessoal de Nível Superior. Plano Nacional de PósGraduação - PNPG 2005/2010. Brasília, DF. 2004.

BRASIL. Ministério da Educação e Cultura. Conselho Nacional de Pós-Graduação. III Plano Nacional de Pós-Graduação. Brasília, DF, 1985. In: BRASIL. Ministério da Educação. Coordenação de Aperfeiçoamento de Pessoal de Nível Superior. Plano Nacional de PósGraduação - PNPG 2005/2010. Brasília, DF. 2004.

CASTRO, J. A., MENEZES, R. M.A Gestão das Políticas Federais para o Ensino Fundamental nos Anos 90. In: Revista Em Aberto, nº75. Brasília, MEC, 2002.

COMISSÃO MISTA CAPES/CNPq para o Desenvolvimento da Pós-Graduação em educação. Plano Nacional de Pós-Graduação: considerações preliminares para o $\mathbf{V}$ PNPG. Brasília: Portaria Interministerial MCT/MEC, n. 270, 22 de maio de 2003, jan. 2004.

KINZO, M. D. G.A democratização brasileira: um balanço do processo político desde a transição. São Paulo Perspec. [online]. 2001, vol.15, n.4, pp. 3-12. ISSN 0102-8839.

LIRA, A. T. N. A legislação da educação no Brasil durante a ditadura militar (1964 1985): um espaço de disputas. Tese de doutorado. Universidade Federal Fluminense (UFF). Niterói, 2010.

SANTANA, A. e MARTINS, H. F. Gestão estratégica de políticas públicas: A Capes e a política de Formação de Recursos Humanos para o desenvolvimento do país. V Congresso de Administração Pública, Brasília, 2012.

SANTOS, A. L.F. e AZEVEDO, J. M. L. A pós-graduação no Brasil, a pesquisa em educação e os estudos sobre a política educacional: os contornos da constituição de um campo acadêmico. Rev. Bras. Educ. [online]. 2009, vol.14, n.42, pp. 534-550.

SOUZA, Donaldo Bello de; FARIA, Lia Ciomar Macedo (orgs). Reforma do Estado, descentralização e municipalização do ensino no Brasil: a gestão política dos sistemas públicos de ensino pós-LDB 9394-96. In: Fundação Cesgranrio. Ensaio: avaliação e políticas públicas em educação. Volume 1, nº1, out. - dez. 2004.

VAROTTO, M. A educação como "salvadora da pátria": Uma análise das políticas educacionais proclamadas pelo Estado Brasileiro, principalmente, na segunda fase do regime militar, a fim de restaurar e renovar sua legitimidade social. Cadernos da Pedagogia ano I Volume 01 Janeiro/Julho de 2007. 
'Dados apresentados pelo presidente da Capes, Lívio Amaral, em 15 de setembro, durante a I Reunião Anual de Ciência, Tecnologia, Inovação e Cultura do Recôncavo Baiano.

ii Segundo o I PNPG, dentro do complexo universitário, a pós-graduação abrange as modalidades de mestrado e doutorado (pós-graduação stricto sensu) e as de aperfeiçoamento e especialização (pós-graduação lato sensu), de acordo com as normas do Conselho Federal de Educação e a legislação em vigor.

iii $10.300 .000 .000,00$ - dez bilhões e trezentos milhões de cruzeiros, na moeda corrente da época.

iv Em 1987, inclusive, o Plano de Metas para Formação de Recursos Humanos e Desenvolvimento Científico (1987/1989) passou a integrar o III PNPG. Entretanto, as metas não foram atingidas devido a restrições orçamentárias. (SANTANA e MARTINS, 2012).

${ }^{v}$ Comissão Mista CAPES/CNPq para o Desenvolvimento da Pós-Graduação e da Ciência e Tecnologia- Portaria Interministerial MCT/MEC, no 270 de 22/05/2003.

vi - CAPES. Discussão da Pós-Graduação Brasileira. Brasília: CAPES/MEC, 1996.

vii - INFOCAPES. Boletim Informativo da CAPES Brasília: CAPES/MEC, 1997 - Edição Comemorativa dos 45 anos.

viii - Decreto de 20 de outubro de 2003. O GTI foi composto por 12 membros, sendo dois representantes de cada um dos órgãos que se seguem: Ministério da Educação; Casa Civil; Secretaria Geral da Presidência da República; Ministério do Planejamento, Orçamento e Gestão; Ministério da Ciência e Tecnologia; Ministério da Fazenda.

${ }^{\text {ix }}$ Lei $\mathrm{n}^{\circ} 10.861$, de 14 de abril de 2004.

${ }^{x}$ Lei $n^{\circ} 11.079$, de 30 de dezembro de 2004.

${ }^{x i}$ Lei $\mathrm{n}^{\circ} 11.096$, de 13 de janeiro de 2005.

${ }^{x i i}$ Decreto ${ }^{\circ} 5.622$, de 19 de dezembro de 2005.

xiii Decreto $\mathrm{n}^{\circ} 5.800$, de 08 de junho de 2006.

${ }^{\text {xiv }}$ Decreto $\mathrm{n}^{\mathrm{0}} 6.096$, de 24 de abril de 2007.

${ }^{\mathrm{xv}}$ Portaria Normativa Interministerial, $\mathrm{n}^{\mathrm{o}} 22$ de 30 de abril de 2007.

${ }^{x v i}$ Portaria Normativa Interministerial, MCT/MEC n ${ }^{\circ} 270$, de 22 de maio de 2003.

${ }^{\text {xvii }}$ Países apontados como competidores em áreas da política industrial: Cingapura, Coréia do Sul, China, Espanha, Índia e Taiwan. 